\title{
Genetic Diversity Analysis and Single-nucleotide Polymorphism Marker Development in Cultivated Bulb Onion Based on Expressed Sequence Tag-Simple Sequence Repeat Markers
}

\author{
John McCallum ${ }^{1}$, Susan Thomson, Meeghan Pither-Joyce, and Fernand Kenel \\ New Zealand Institute for Crop and Food Research Limited, Plant and Food Biotechnology, Private \\ Bag 4704, Christchurch, 8140 New Zealand \\ Andrew Clarke \\ Allan Wilson Centre, Institute of Molecular BioSciences, Massey University, Private Bag 11222 , \\ Palmerston North, New Zealand \\ Michael J. Havey \\ USDA-ARS, Department of Horticulture, University of Wisconsin, Madison, WI 53706
}

\begin{abstract}
AdDitional INDEX wORDs. simple sequence repeat, heterozygosity, EST
Abstract. Bulb onion (Allium cepa L.) is a globally significant crop, but the structure of genetic variation within and among populations is poorly understood. We broadly surveyed genetic variation in a cultivated onion germplasm using simple sequence repeat (SSR) markers and sequenced regions flanking expressed sequence tag (EST)-SSRs to develop single-nucleotide polymorphism (SNP) markers. Samples from 89 inbred and open-pollinated (OP) bulb onion populations of wide geographical adaptation and four related Allium L. accessions were genotyped with 56 ESTSSR and four genomic SSR markers. Multivariate analysis of genetic distances among populations resolved long-day, short-day, and Indian populations. EST-SSR markers frequently revealed two major alleles at high frequency in OP populations. The median proportion of single-locus polymorphic loci was 0.70 in $O P$ and landrace populations compared with 0.43 in inbred lines. Resequencing of 24 marker amplicons revealed additional SNPs in 17 (68\%) and five SNP assays were developed from these, suggesting that resequencing of EST markers can readily provide SNP markers for purity testing of inbreds and other applications in Allium genetics.
\end{abstract}

Bulb onion is one of the most widely cultivated vegetables but is poorly characterized at the genetic level. It is a biennial, outcrossing diploid that exhibits severe inbreeding depression (Havey, 1993) and is traditionally propagated from seed produced by insect crosspollination of large populations. Increasingly, commercial breeding is focused on $\mathrm{F}_{1}$ hybrids based on cytoplasmic male sterility, which necessitates inbreeding to fix nuclear restorer loci (Berninger, 1965; Jones and Clarke, 1943). Shallot (Allium cepa Aggregatum group) is a morphologically distinctive but closely related horticultural type that is mostly propagated asexually, although fertile types can freely intercross with bulb onion (Rabinowitch and Kamenetsky, 2002). As a result of a lack of wild relatives, poor representation in genetic resource collections (Cross, 1998; Kik, 2008), and the expense of asexual or seed maintenance of $A$. серa germplasm, it is desirable to better understand the population structure of global resources to better target maintenance and exploitation. A more detailed understanding of genetic variation within and among populations is also required to develop marker-based

Received for publication 9 June 2008. Accepted for publication 30 Sept. 2008. This research was funded by the New Zealand Foundation for Research Science and Technology contract C02X0203.

We gratefully acknowledge the provision of germplasm surveyed in this study by Cornell University, Terranova Seeds, New Zealand, Tropicasem Ltd., Senegal, and other collaborators.

${ }^{1}$ Corresponding author. E-mail: mccallumj@crop.cri.nz. methods for testing purity and authenticity of commercial inbreds and hybrids.

Studies of genetic diversity in onion have been hampered by a lack of portable codominant molecular markers (McCallum, 2007). Although a variety of molecular marker methods have been successfully used to resolve questions of genetic diversity and relatedness to species level in Allium (Klaas and Friesen, 2002), identifying robust and informative markers within $A$. cepa has proved much more challenging. Dominant randomly applied polymorphic DNA markers have been used in limited studies of $A$. серa diversity (Dennequin et al., 1997; Tanikawa et al., 2002), but a more detailed evaluation by Bradeen and Havey (1995a) showed that identification of reliable, heritable polymorphisms is very challenging in onion. Isozyme (Cramer and Havey, 1999; Rouamba et al., 2001) and restriction fragment length polymorphism (RFLP) (Bark and Havey, 1995) markers have been used but are limited, respectively, by low polymorphism (Peffley and Orozco-Castillo, 1987) and the unusually large genome size typical of Allium species (Bennett and Leitch, 1995). Fischer and Bachmann (2000) reported development of a set of genomic dinucleotide simple sequence repeat (SSR) markers from onion. As a result of complex amplification requirements, these markers have not proved sufficiently portable to enable wider use in mapping and diversity studies, although Masuzaki et al. (2006a) reported optimization and chromosomal allocation of a subset of these. More recently, SSR and single-nucleotide polymorphism 
(SNP) markers have been developed from onion expressed sequence tag (EST) resources (Kuhl et al., 2004; Martin et al., 2005) and proved to be readily reproducible for mapping (McCallum et al., 2006a, 2006b) and cultivar discrimination (Jakse et al., 2005).

The goal of this study was to perform a broad survey of genetic variation within and among cultivated onion populations and assess potential of EST-derived markers for genetic identity testing. To permit a sufficiently broad survey and ensure relevance for seedlot identity testing, we estimated allele numbers in bulked samples, an approach previously used in similar surveys of maize (Zea mays L.) diversity. This revealed high levels of within-population heterozygosity and limited EST-SSR size polymorphism in cultivated onion. The results suggest that discrimination of inbred onion lines with SNP markers will be feasible and that such markers can be readily developed from onion EST resources.

\section{Methods and Materials}

Plant materials. A set of 82 bulb onion populations was selected to represent the broadest possible range of germplasms relevant to modern genetics and breeding, including mapping population parents, inbred and open-pollinated (OP) populations widely exploited by breeders and landraces. A supplementary table containing full details of this material is available online at www.ASHS.org. Seven doubled haploid (DH) bulb onion lines were obtained from Cornell University (Alan et al., 2004). Four

Table 1. Simple sequence repeat (SSR) primer sets developed from onion sequence resources for genetic diversity analysis of onion and Allium relatives.

\begin{tabular}{|c|c|c|c|c|}
\hline Primer set & Type $^{z}$ & Genbank accession no. & $\begin{array}{l}\text { Forward primer sequence } \\
\text { Reverse primer sequence }\end{array}$ & Expected size (bp) \\
\hline \multirow[t]{2}{*}{ ACM004 } & EST-SSR & BI095629 & TCGTTCTTTAGAACACGTTAGG & 214 \\
\hline & & & GTCGGCGGATATAGTGACA & \\
\hline \multirow[t]{2}{*}{ ACM018 } & EST-SSR & CF438995 & GGGGAATGGTGGAGAATAGA & 300 \\
\hline & & & AACAGAGGCAAGAGGAGCG & \\
\hline \multirow[t]{2}{*}{ ACM046 } & EST-SSR & CF439398 & TCCTCGTCACCACCACAG & 280 \\
\hline & & & CTGAAAGGGAGTAGCGGAG & \\
\hline \multirow[t]{2}{*}{ ACM050 } & EST-SSR & CF438491 & GGTTCTCTGTTTGGGACA & 277 \\
\hline & & & CCGTTTCGGCTACCTTGTAT & \\
\hline \multirow[t]{2}{*}{ ACM065 } & EST-SSR & CF449328 & GCTCTGATGGAGGATGGTTC & 197 \\
\hline & & & CTTGCCATCTTTGTCGGT & \\
\hline \multirow[t]{2}{*}{ ACM068 } & EST-SSR & CF450463 & GAAGGTGAAGGTGTACGGT & 261 \\
\hline & & & CAAATGGCTGCAATAAGCAA & \\
\hline \multirow[t]{2}{*}{ ACM183 } & EST-SSR & CF443106 & GATGATGGTGATGGCATTGA & 213 \\
\hline & & & GTTTGCAGGCTCCATTGATT & \\
\hline \multirow[t]{2}{*}{ ACM187 } & EST-SSR & CF446468 & GTACTCGGGCAGTGGAGGTA & 246 \\
\hline & & & GGAGCTGTCCAAATGCTAGG & \\
\hline \multirow[t]{2}{*}{ ACM227 } & EST-SSR & CF439865 & AGCAGCTCATTCAGCAAAA & 198 \\
\hline & & & GAGGTCGGAGAAGGAGGAGT & \\
\hline \multirow[t]{2}{*}{ ACM238 } & EST-SSR & CF443464 & TGATAGCCAGTTGATTGCGA & 261 \\
\hline & & & TTCCCCAGTACACACCTTCC & \\
\hline \multirow[t]{2}{*}{$\mathrm{ACM} 240$} & EST-SSR & CF444554 & GTGCAACTCCAAGAGAAGGG & 194 \\
\hline & & & AATATAAAGGCGTTGGCCTG & \\
\hline \multirow[t]{2}{*}{ ACM243 } & EST-SSR & CF445129 & ATCAGGAGGTTCGAGGAAA & 141 \\
\hline & & & TCATTCGTATCATTTGCGGT & \\
\hline \multirow[t]{2}{*}{ ACM295 } & EST-SSR & CF437320 & AGATCCGTCCCATGAAACT & 146 \\
\hline & & & GATCCGCTTCTGAAATCTCG & \\
\hline \multirow[t]{2}{*}{ ACM300 } & EST-SSR & CF448987 & AGGTGCAGTTTCGTGGTAGG & 154 \\
\hline & & & TTAGCCCCTGGTAAGTGTGG & \\
\hline \multirow[t]{2}{*}{ ACM301 } & EST-SSR & CF434545 & TGGAGTCAAAAGGTGGTGAA & 109 \\
\hline & & & TTCTTGATTCCTCCGTTTGG & \\
\hline \multirow[t]{2}{*}{ ACM303 } & gSSR & DQ273270 & CGATGATTATAGATATTTCGTTATGG & 115 \\
\hline & & & CATTCATAATCTCACAGTGGAAGG & \\
\hline \multirow[t]{2}{*}{ ACM315 } & EST-SSR & ES449741 & TTTTCTCCACCTTCAGCCAG & 269 \\
\hline & & & AGAAATGGTGGTCGAGGATG & \\
\hline \multirow[t]{2}{*}{ ACM316 } & EST-SSR & ES449430 & TGGATCATAAAAAGCGGCAT & 204 \\
\hline & & & GAAGAGGCTTTTTCCGGACT & \\
\hline \multirow[t]{2}{*}{ ACM318 } & EST-SSR & ES449367 & TCСТССТТССАААССАСАТС & 243 \\
\hline & & & GATCAGAAACAGCAGCGTC & \\
\hline \multirow[t]{2}{*}{ ACM326 } & EST-SSR & CF437364 & AAACCAGCAACAACCAATG & 200 \\
\hline & & & AAAATTGGAGAGCAGGCAAA & \\
\hline
\end{tabular}

${ }^{\mathrm{z} E S T-S S R}$ and gSSR denote SSR markers developed, respectively, from expressed sequence tag (EST) and genomic sequence resources, respectively. 
है।

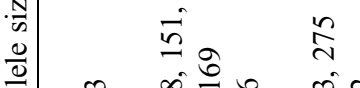

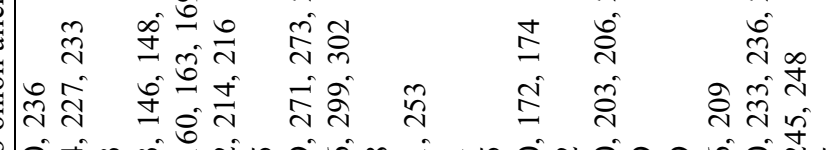

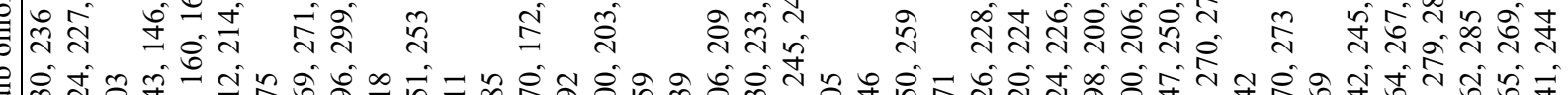

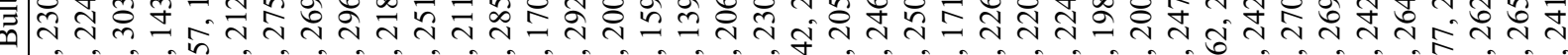

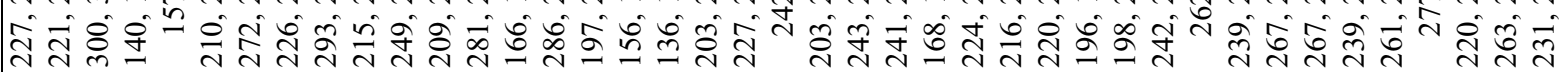

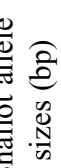

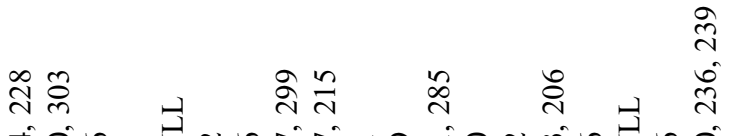

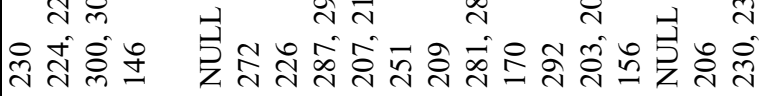

交㞧航

๙ิ

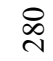

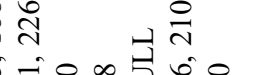

ते ते ते

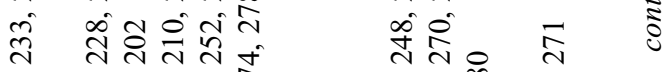

$\frac{1}{8}$

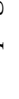

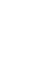

$\div$

$\frac{\infty}{\square}$

त्:

赵|

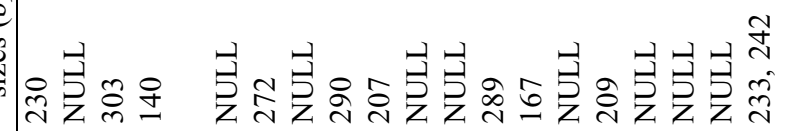

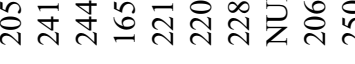

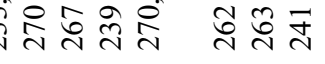

$\frac{0}{\pi}$

$\overbrace{}^{2}$

空

章

产

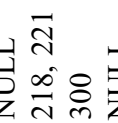

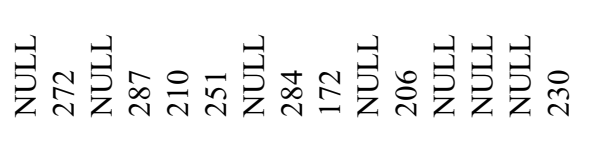

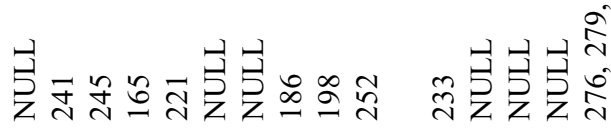

通完岂

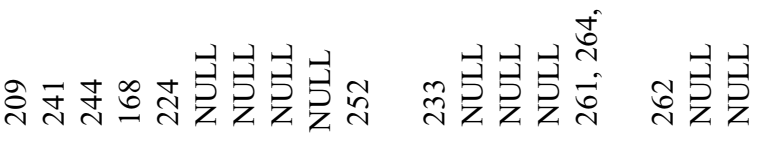

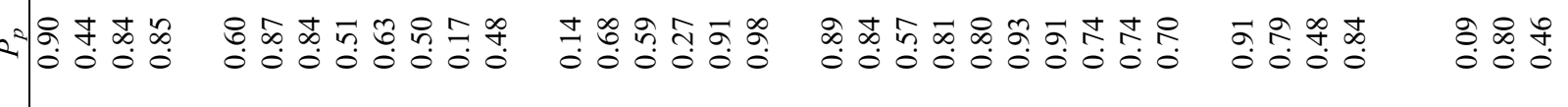

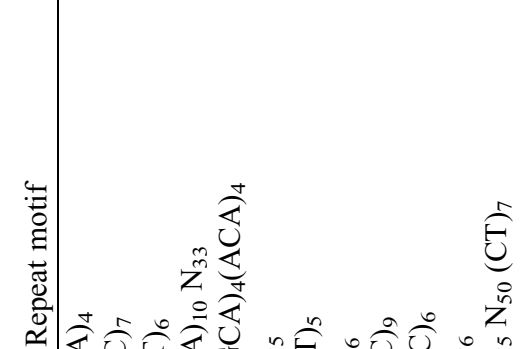

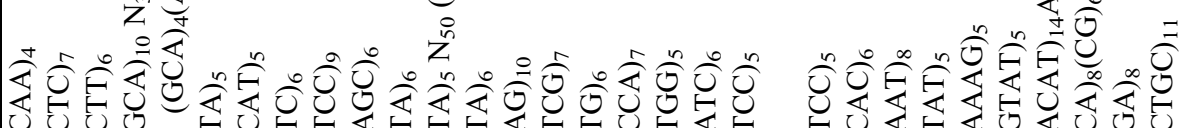

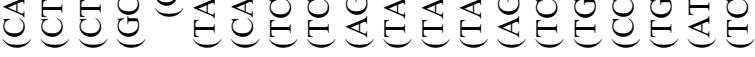

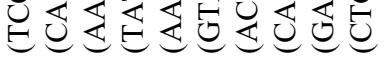

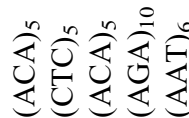

它察它 


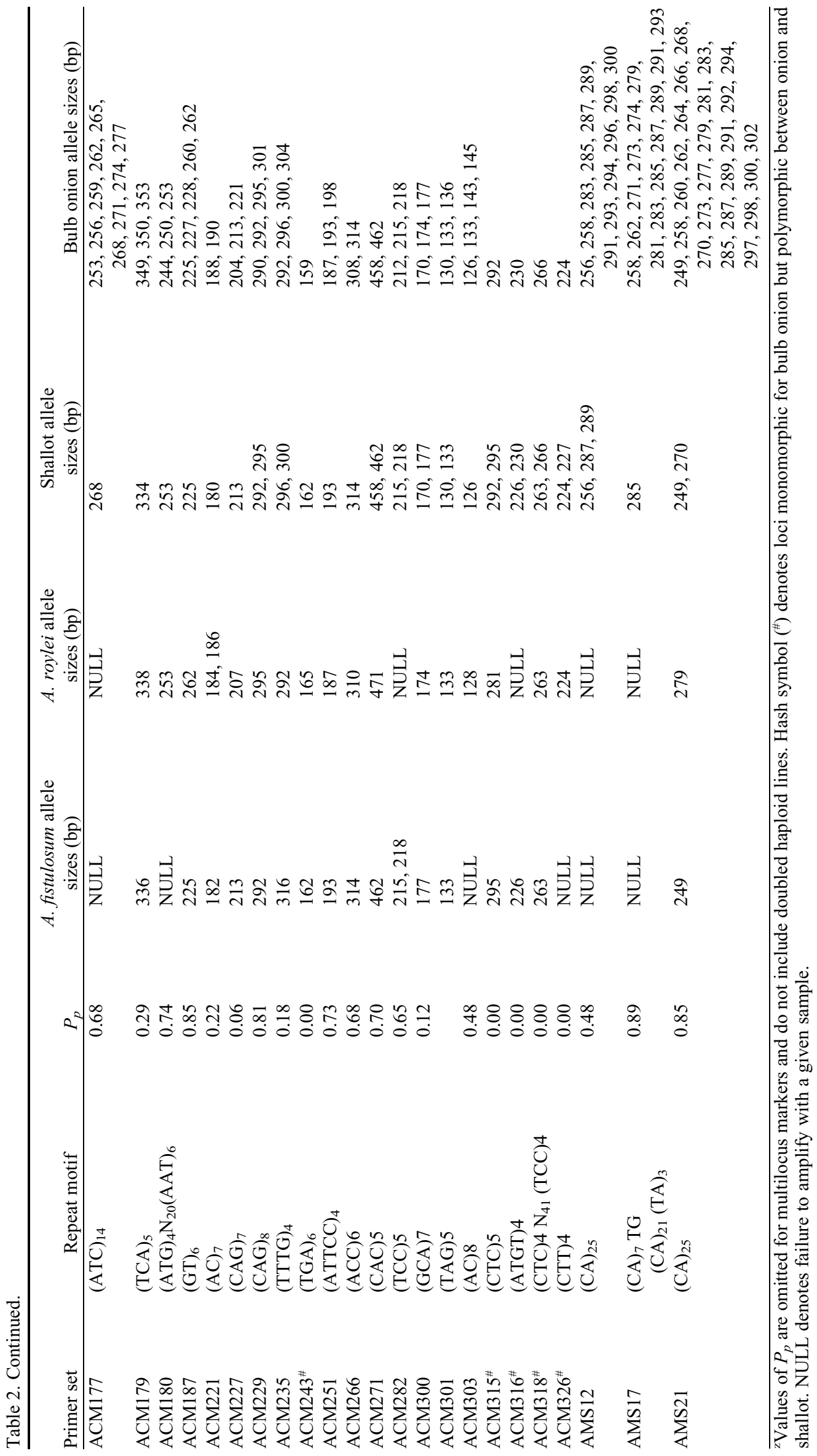


related Allium outgroups were provided by single accessions of A. fistulosum L. (Ohara et al., 2005), A. roylei Stern (van der Meer and de Vries, 1990), shallot (A. cepa L. aggregatum group), and the amphidiploid between $A$. cepa and A. fistulosum 'Beltsville Bunching' (Jones and Clarke, 1942). DNA samples used were either isolated in earlier studies (Bark and Havey, 1995; Bradeen and Havey, 1995b; Havey, 2000; Leite et al., 1999 ) or purified from bulked tissue of at least 25 seedlings as described previously (McCallum et al., 2006a).

CDNA LIBRARY DEVELOPMENT. Immature, unopened flower buds were pooled in Dec. 2004 from multiple genotypes that included maintainer and restorer lines in nitrogen and sulfur cytoplasm. Total RNA was isolated as described previously (McCallum et al., 2002) and a nonnormalized cDNA library was constructed in pCMV.SPORT 6.1 (Invitrogen, Carlsbad, CA). Random clones (672) were purified using NucleoSpin 96 Flash Kit (Macherey-Nagel, Duren, Germany) and sequenced from the 5' end using Big Dye version 3.0 chemistry (Applied Biosystems, Foster City, CA). Trimmed reads were submitted to the Genbank EST division (accession numbers ES449250 to ES449826).

Marker analysis. EST-SSR primer sets were described previously (Kuhl et al., 2004; Martin et al., 2005; McCallum et al., 2006a, 2006b) or designed as described previously (Kuhl et al., 2004) from floral EST and other onion EST resources (Table 1). Genomic SSR primer sets were those originally reported by Fischer and Bachmann (2000) and chromosomally assigned by Masuzaki et al. (2006b). Polymerase chain reaction (PCR) amplification and analysis of SSR products was performed as described previously (Martin et al., 2005) with the following modifications. Primer ratios were modified from the method of Schuelke (2000) to use marker tailed forward plus reverse primers at $0.5 \mu \mathrm{M}$ and fluorescently labeled universal primer at $0.2 \mu \mathrm{M}$. A "PIG-tail" sequence (GTTTCTT) was added to the $5^{\prime}$ end of reverse primers to minimize variability in nontemplated adenylation of amplicons (Brownstein et al., 1996).

Chromatograms were analyzed using visual and quantitative tools provided in GeneMarker (version 1.42; SoftGenetics, State College, PA). Peak interpretation was guided by reference to prior segregation data from mapping populations (Martin et al., 2005; McCallum et al., 2006a) and DH controls. Analyses were restricted to measures of allele presence judged on conservative criteria. Principal coordinates analysis (PCO) was performed in Genstat (Payne et al., 2006) on the similarity matrix calculated from 289 peaks revealed by 60 primer sets using the Jaccard coefficient. A total of 51 primer sets (48 ESTSSRs, three genomic SSRs), which yielded profiles of quality 1 or 2 , as defined by Leigh et al. (2003), which could be reliably scored as single loci, were used to estimate population heterozygosity as the proportion of polymorphic loci $\left[P_{l}(\right.$ Berg and Hamrick, 1997)].

RESEQUENCING OF MARKER LOCI. A small subset of two to four templates was selected for resequencing, including a DH line and one or more populations exhibiting high frequencies of an alternate size allele. PCR products were purified using the High Pure PCR Product Purification Kit (Roche Diagnostics, Mannheim, Germany) following the manufacturer's instructions and cloned into pGEM-T Easy Vector (Promega, Madison, WI). DNA for sequencing was amplified directly from at least eight white colonies from each template using the Templiphi Amplification Kit (Amersham Biosciences, Piscataway, NJ).
Sequencing was performed with M13 forward and reverse primers using a Big Dye version 3.0 cycle sequencing kit (Applied Biosystems) and analyzed on an ABI3100 Genetic Analyser (Applied Biosystems). Sequence comparison and SNP detection was carried out using SeqScape version 2.1 (Applied Biosystems) using Genbank sequences of ESTs used in original primer design as reference sequences.

Single-NUCleotide POLYMORPHISM ASSAY DESIGN. Restriction polymorphisms were identified using BlastDigester (Ilic et al., 2004) and if suitable polymorphisms could not be

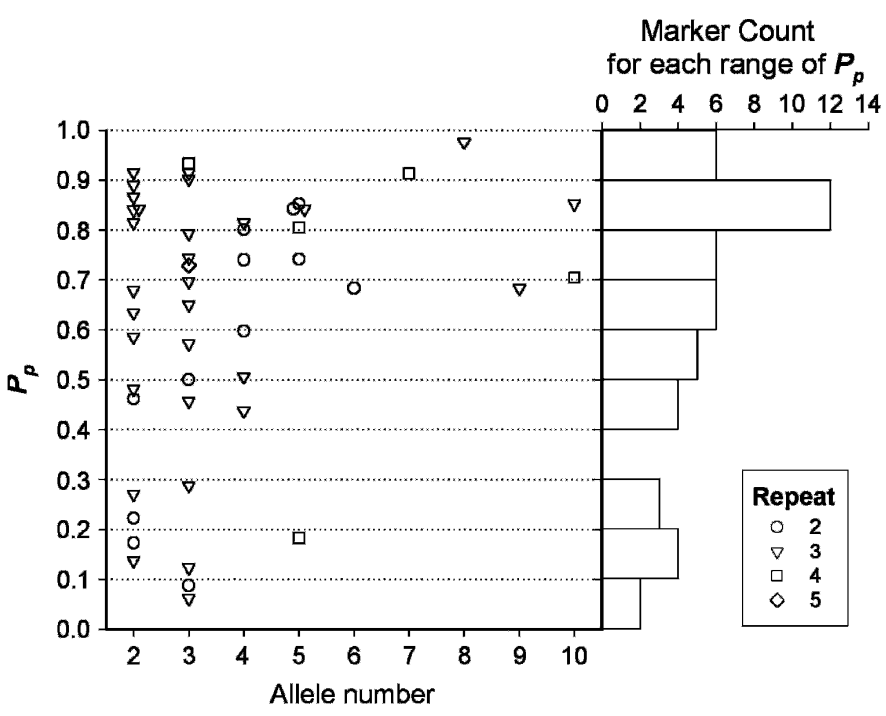

Fig. 1. Distribution of proportion of polymorphic populations $\left(P_{p}\right)$ revealed by 48 single-locus expressed sequence tag-simple sequence repeat (EST-SSR) markers among 82 bulb onion populations plotted by observed allele number and repeat unit.

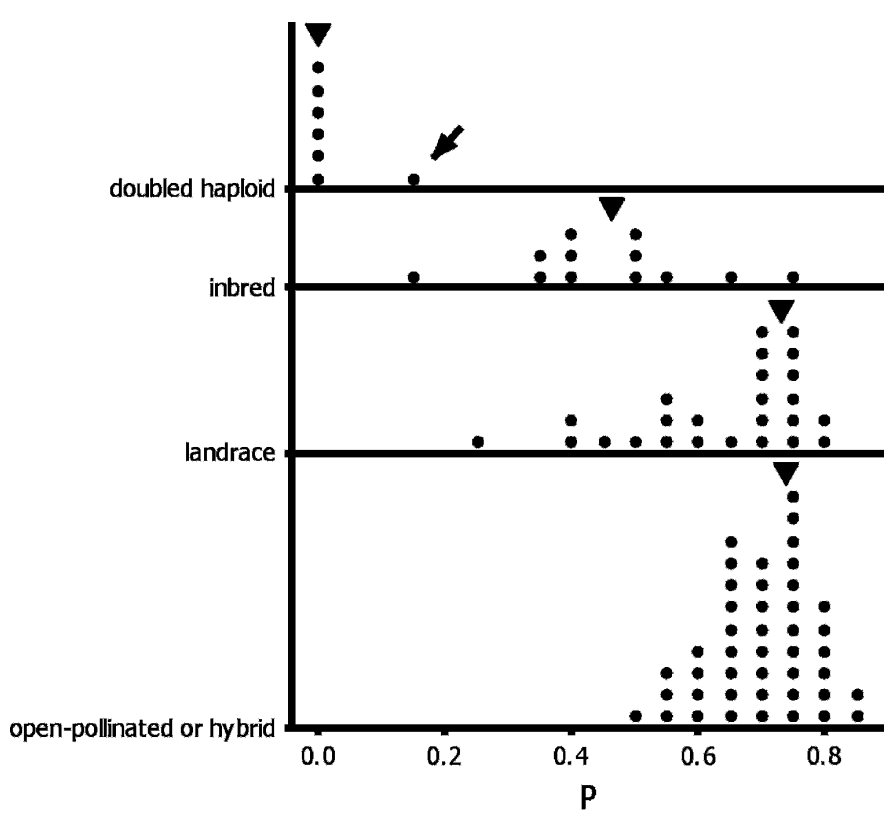

Fig. 2. Distribution of observed proportion of polymorphic loci $\left(P_{l}\right)$ for 89 bulb onion accessions (seven doubled haploid, 12 inbred, 25 landrace, and 45 openpollinated) evaluated at 51 simple sequence repeat (SSR) loci. Triangles denote medians and arrowhead denotes a doubled haploid line believed to have been contaminated during seed production. 
identified, potential for engineering these was identified using dCAPS finder 2.1 (Neff et al., 2002). Cleaved amplified polymorphic sequence or derived cleaved amplified polymorphic sequence primer sets for assaying the polymorphisms were designed using Primer 3 software (Rozen and Skaletsky, 2000). Ability of assays to reveal polymorphisms within bulb onion was confirmed by genotyping a small subset of surveyed germplasm, including a DH control.

\section{Results and Discussion}

DISTRIBUTION OF POLYMORPHISM WITHIN AND AMONG BULB ONION. We screened a total of 76 EST-SSR and 12 genomic SSR markers for ability to reveal polymorphism in this set of accessions and used data from 56 EST-SSR and four genomic SSR primer sets, which revealed reproducible patterns. Presence of DH lines in the panel greatly aided interpretation of chromatograms, because visual evaluation of aligned chromatograms suggested a high frequency of heterozygosity for most markers. As observed during earlier mapping studies (Martin et al., 2005), ESTSSR markers designed using standard criteria performed well across onion germplasm under uniform PCR conditions. Amplicons of similar size were amplified in the related species $A$. roylei and $A$. fistulosum by 33 and 32 of these markers, respectively, confirming their value for interspecific and comparative studies. By contrast, dinucleotide genomic SSRs (gSSRs) required optimization of conditions and amplified rarely in allied Allium species. Chromatograms of gSSRs revealed much higher levels of size polymorphism than EST-SSR but were more challenging to interpret in population bulk samples as a result of high levels of stutter such that only three were selected for estimation of locus heterozygosity. EST-SSR primer sets revealed an average of 3.59 alleles (range, one to 10 alleles), similar to the distribution observed in durum wheat (Triticum aestivum L.) EST-SSRs by Wang et al. (2007) with diand trinucleotide SSRs revealing similar ranges of polymorphism (Table 2; Fig. 1). Five primer sets were monomorphic in bulb onion but revealed polymorphism between bulb onion and Allium outgroups.

Population heterozygosity in the bulb onion accessions (excluding DH lines) was conservatively estimated as $P_{l}$ revealed by 51 of the 60 markers (219 alleles), which revealed variation in bulb onion that could be confidently interpreted as representing alleles at one locus. Because we expect that alleles with frequencies below $5 \%$ may not be detected in a bulk PCR, this estimate of heterozygosity is conservative but directly relevant to PCRbased discrimination and authenticity testing of bulked seed samples. The heterozygosity detected by markers in the 82 nonDH bulb onion populations, expressed as the proportion of heterozygous populations $\left(P_{p}\right)$, shows a bimodal distribution (histogram in Fig. 1). The markers that detected polymorphism in less than $30 \%$ of populations surveyed were characterized by rare informative alleles, whereas the majority were characterized by several alleles at high frequency across the populations. Bulb onion populations exhibited a wide range of heterozygosity with $P_{l}$ ranging from 0.12 to 0.84 (Fig. 2). Median $P_{l}$ in landrace and OP or hybrid populations was 0.7 compared with 0.43 in the sample of inbred lines. The range of $P_{l}$ observed in the noninbred populations is at the high end of the range observed in isozyme studies of outcrossing species (Berg and Hamrick, 1997;

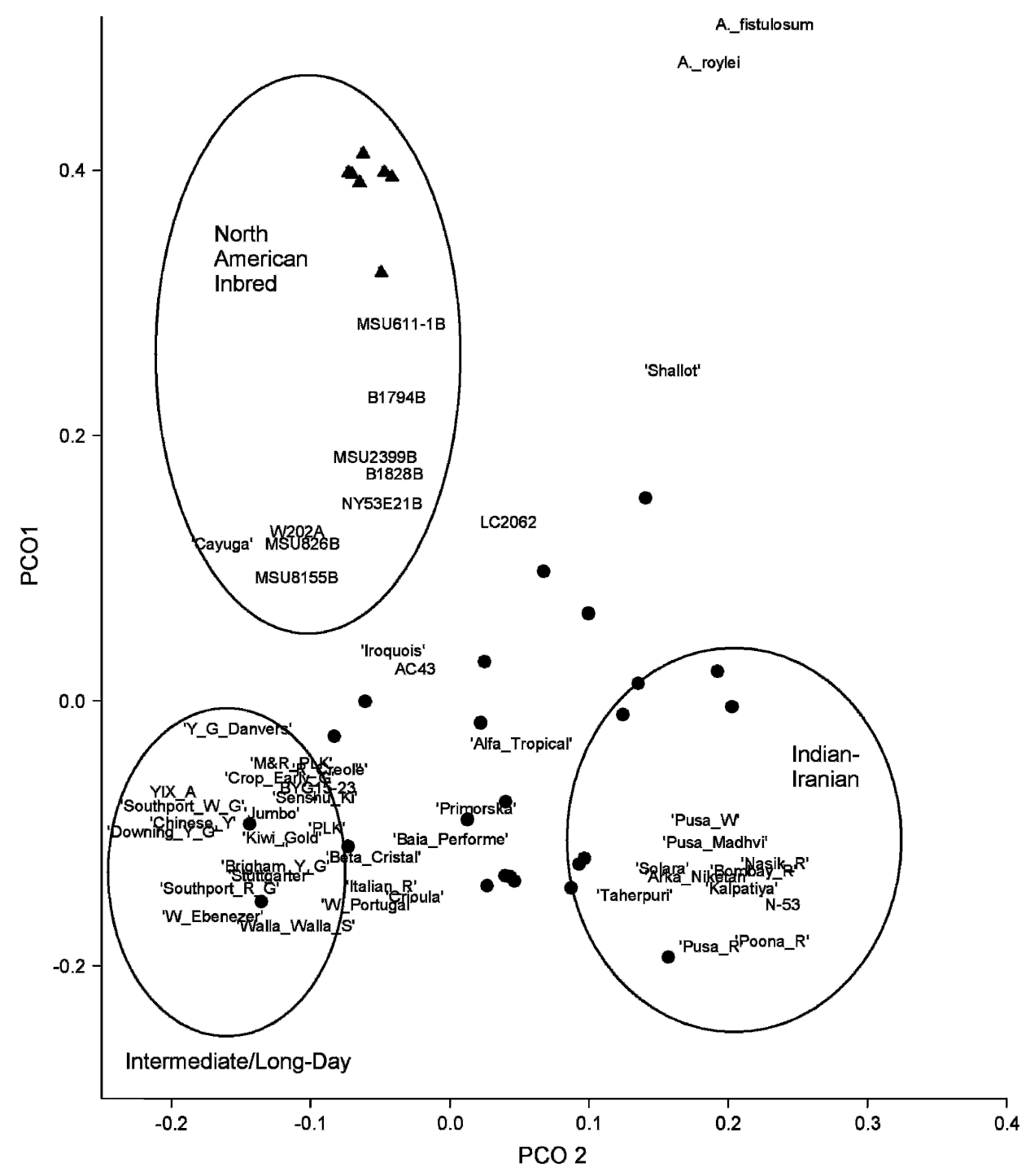

Fig. 3. Principal coordinates (PCO) ordination of Jaccard similarity matrix for 89 bulb onion and four related Allium accessions calculated from all 289 polymorphic peaks revealed by 60 simple sequence repeat (SSR) markers. Common words in cultivar names were abbreviated as follows: $\mathrm{R}=$ red, $\mathrm{W}=$ white, $\mathrm{Y}=$ yellow, $\mathrm{G}=$ globe, $\mathrm{S}=$ sweet. Triangles denote Cornell University doubled haploid lines and dots denote unnamed accessions from USDA-ARS germplasm collections with PI numbers. 
Hamrick and Godt, 1989). The wide range of $P_{l}$ observed in the inbred lines is consistent with the fact that inbred development in onion can involve a wide range of bottlenecks, ranging from limited mass pollinations of three to 20 plants to one or more cycles of self-pollination. The narrower range of $P_{l}$ in OP cultivars and breeding populations compared with landraces may reflect the success of modern plant breeding in increasing heterozygosity through intercrossing and selection for vigor. The DH line DH2178 showed heterozygosity at a few loci, which is believed to have arisen from crosscontamination in seed production (M. Mutschler, personal communication).
These observations of high heterozygosity and low allele number confirm the previous report of Bark and Havey (1995), who commonly observed two alleles using RFLP and together suggest that allelic diversity in onion is lower than in maize. Similar genotyping of bulked samples has been widely used and well proven in maize (Reif et al., 2005), but more detailed analysis of allele frequencies within populations is required to provide a more quantitative picture of heterozygosity in breeding and landrace onion germplasm.

Multivariate ANALYSIS OF MARKer DATA. The complete data set comprising presence/absence data for 289 peaks scored on all 60 markers was subjected to multivariate analysis of the Jaccard similarity matrix. PCO was used for ordination and exploration of the similarity matrix (Fig. 3). The first PCO explaining $15 \%$ of the variability was highly correlated $(\mathrm{r}=-0.95)$ with $P_{l}$, indicating that this component represents differences in heterozygosity. The second PCO ( $7 \%$ of variation) provides resolution of populations congruent with their known geographical origins. In particular, long- and intermediate-day types originating from temperate growing regions are resolved from short-day (SD) tropical types. However, the most notable feature of this ordination is the clear resolution of a group of Indian cultivars and landraces from the main grouping of SD populations. This grouping may represent populations more closely related to ancestral bulb onion types from the center of origin. The survey of $A$. cepa by Fischer and Bachmann (2000), based on genomic SSRs, also revealed groupings related to geographical origin but focused on shallot and landrace onion germplasm, making comparison with our findings difficult.

No polymorphisms were identified in regions flanking SSRs in the markers ACM033, ACM066, ACM094, ACM115, ACM154, ACM229, and ACM245.

Table 4. Cleaved amplified polymorphic sequence (CAPS) and derived CAPS (dCAPS) markers developed from single-nucleotide polymorphisms (SNPs) in regions flanking simple sequence repeats (SSRs) in onion expressed sequence tag (EST)-SSR markers.

\begin{tabular}{|c|c|c|c|c|c|}
\hline $\begin{array}{l}\text { Assay } \\
\text { primer Set }\end{array}$ & $\begin{array}{l}\text { Parent primer } \\
\text { set }\end{array}$ & $\begin{array}{c}\text { eference sequen } \\
\text { Genbank } \\
\text { accession no. }\end{array}$ & $\begin{array}{c}\text { Target } \\
\text { polymorphism }\end{array}$ & $\begin{array}{l}\text { Forward and reverse } \\
\text { primer sequences }\end{array}$ & Type \\
\hline ACM006 & - & BQ580184 & G126C & See Kuhl et al. (2004) & Taq1 CAPS \\
\hline ACP014 & ACM183 & CF443106 & G105A & $\begin{array}{l}\text { GACGACAACAATGATAATATAGATACTCG } \\
\text { AATTGTTTGCAGGCTCCATT }\end{array}$ & Xhol dCAPS \\
\hline ACP015 & ACM093 & CF445996 & C58T & $\begin{array}{l}\text { TACTATACCGGCCACCACGA } \\
\text { TATTCTCTTCGGCTTTCGTGA }\end{array}$ & MboI dCAPS \\
\hline ACP017 & ACM227 & CF439865 & G99A & $\begin{array}{l}\text { ACCTTCCCAACAGCACGC } \\
\text { GAGGTCGGAGAAGGAGGAGT }\end{array}$ & Hhal dCAPS \\
\hline
\end{tabular}



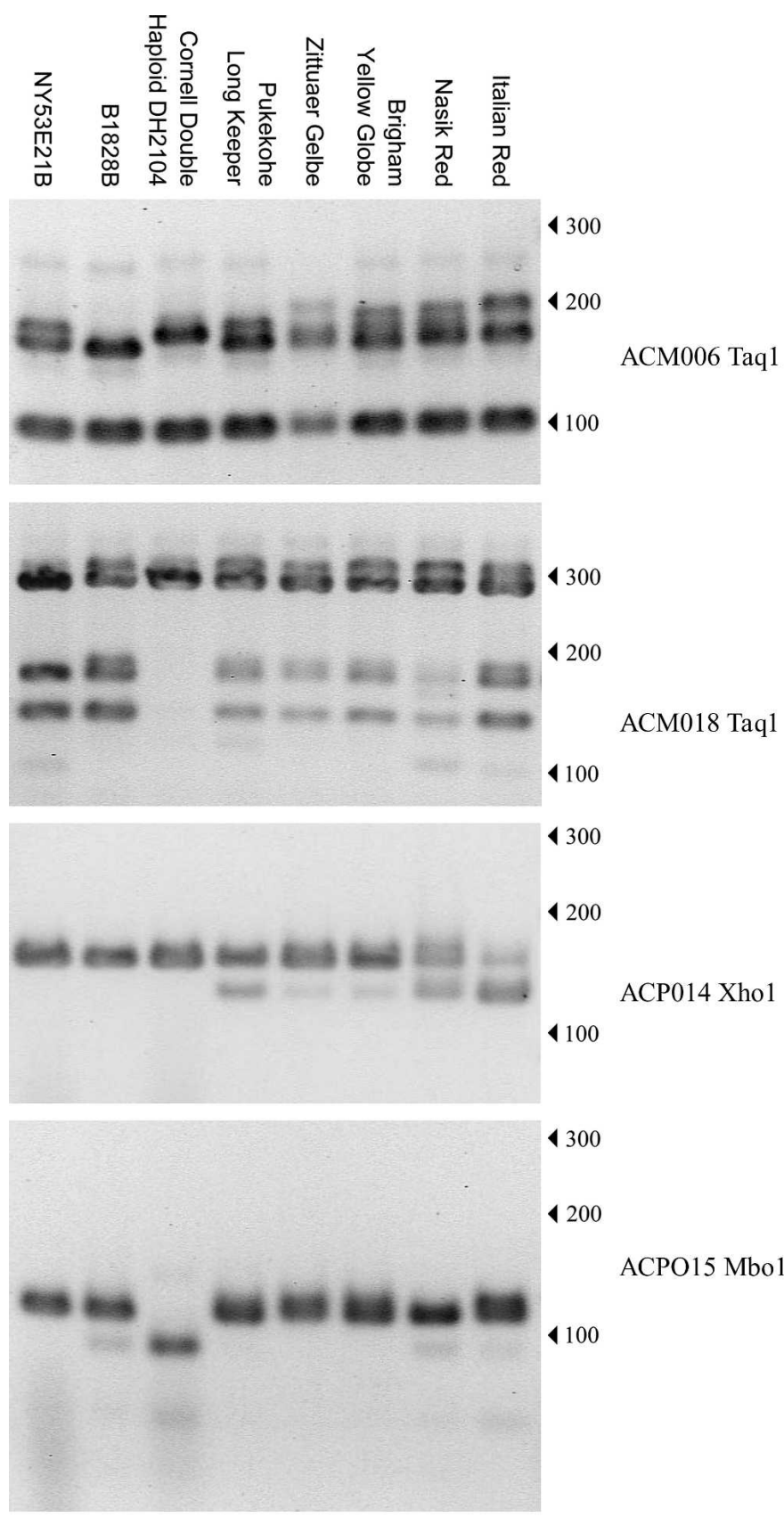

ACPO15 Mbol

300

200

ACP017 Hha1

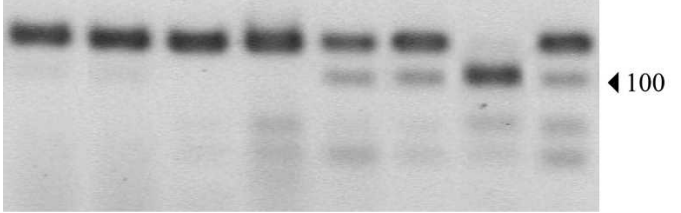

Fig. 4. Single-nucleotide polymorphisms (SNPs) revealed in a set of onion lines by cleaved amplified polymorphic sequence (CAPS) assays developed by resequencing onion expressed sequence tag-simple sequence repeat (ESTSSR) markers. Approximate migration of DNA size standards in basepairs indicated on right.
DEVELOPMENT OF SINGLE-NUCLEOTIDE POLYMORPHISM MARKERS BY EXPRESSED SEQUENCE TAG-SIMPLE SEQUENCE REPEAT RESEQUENCING. After observations of relatively low size allelic diversity revealed by EST-SSR markers, we conducted resequencing to determine whether these might provide a source of biallelic SNP markers more suitable for commercial and research purposes. Additional polymorphisms were identified in 17 of 24 loci sequenced [ $68 \%$ (Table 3 )] suggesting that more general mutation scanning of $5^{\prime}$ UTR regions of onion genes may provide more polymorphic markers than sizing alone. From these, five polymorphic SNP assays were developed (Table 4; Fig. 4), suggesting that the existing onion EST resources can readily provide many more such markers if properly exploited. Although the levels of diversity observed in noninbred populations would make marker-based purity and authenticity testing using such markers inefficient, the higher levels of fixation observed among inbred lines (Fig. 2) suggests that testing inbreds and their derived hybrids with such singlelocus markers derived from highly heterozygous loci would be quite practical. To improve the efficiency of such an approach, key inbreds could also be subjected to marker-aided inbreeding at one or more loci, as proposed by Tsukazaki et al. (2006) for A. fistulosum. Bunching onion appears to be more tolerant of inbreeding than onion, and therefore some validation that inbreeding did not compromise fitness would be required.

These observations have implications for conservation and exploitation of genetic diversity in onion. In particular, the observation of high allelic diversity in OP populations confirms that these are key reservoirs of diversity in onion worthy of conservation. The lower values of heterozygosity observed in inbreds illustrate the potential for erosion of diversity associated with hybrid breeding. The observation that Indian populations form a genetically distinctive group suggests that this region may have potential to provide novel germplasm resources to broaden the base for breeding and genetic studies in bulb onion.

\section{Literature Cited}

Alan, A.R., A. Brants, E. Cobb, P.A. Goldschmied, M.A. Mutschler, and E.D. Earle. 2004. Fecund gynogenic lines from onion (Allium cepa L.) breeding materials. Plant Sci. (Shannon) 167:10551066.

Bark, O.H. and M.J. Havey. 1995. Similarities and relationships among populations of the bulb onion as estimated by nuclear RFLPs. Theor. Appl. Genet. 90:407-414.

Bennett, M.D. and I.J. Leitch. 1995. Nuclear DNA amounts in angiosperms. Ann. Bot. (Lond.) 76:113-176.

Berg, E.E. and J.L. Hamrick. 1997. Quantification of genetic diversity at allozyme loci. Can. J. For. Res. 27:415-424.

Berninger, E. 1965. Contribution a l'etude de la sterilite-male de l'oignon (Allium cepa L.). Annales d'Amelioration des Plantes 15:183-199.

Bradeen, J.M. and M.J. Havey. 1995a. Randomly amplified polymorphic DNA in bulb onion and its use to assess inbred integrity. J. Amer. Soc. Hort. Sci. 120:752-758.

Bradeen, J.M. and M.J. Havey. 1995b. Restriction fragment length polymorphisms reveal considerable nuclear divergence within a well-supported maternal clade in Allium section cepa (Alliaceae). Amer. J. Bot. 82:1455-1462.

Brownstein, M.J., J.D. Carpten, and J.R. Smith. 1996. Modulation of non-templated nucleotide addition by taq DNA polymerase: Primer modifications that facilitate genotyping. Biotechniques 20:10041006, 1008-1010. 
Cramer, C.S. and M.J. Havey. 1999. Morphological, biochemical, and molecular markers in onion. HortScience 34:589-593.

Cross, R.J. 1998. Global genetic resources of vegetables. Plant Var. Seeds 11:39-60.

Dennequin, M.L., O. Panaud, T. Robert, and A. Ricroch. 1997. Assessment of genetic relationships among sexual and asexual forms of Allium cepa using morphological traits and RAPD markers. Heredity 78:403-409.

Fischer, D. and K. Bachmann. 2000. Onion microsatellites for germplasm analysis and their use in assessing intra- and interspecific relatedness within the subgenus Rhizirideum. Theor. Appl. Genet. 101:153-164.

Goldman, I.L. 1996. A list of germplasm releases from the university of Wisconsin onion breeding program, 1957-1993. HortScience 31:878-879.

Hamrick, J.L. and M.J.W. Godt. 1989. Allozyme diversity in plant species, p. 43-63. In: Brown, A.H.D., M.T. Clegg, A.L. Kahler, and B.S. Weir (eds.). Plant population genetics, breeding, and genetic resources. Sinauer Assoc., Sunderland, MA.

Havey, M.J. 1993. Onion breeding, p. 35-49. In: Kalloo, G. and B. Berg (eds.). Genetic improvement of vegetable crops. Pergamon Press, Oxford, UK

Havey, M.J. 2000. Diversity among male-sterility-inducing and malefertile cytoplasms of onion. Theor. Appl. Genet. 101:778-782.

Ilic, K., T. Berleth, and N.J. Provart. 2004. BlastDigester-A webbased program for efficient CAPS marker design. Trends Genet. 20:280-283.

Jakse, M., W. Martin, J. McCallum, and M. Havey. 2005. Single nucleotide polymorphisms, indels, and simple sequence repeats for onion cultivar identification. J. Amer. Soc. Hort. Sci. 130:912-917.

Jones, H.A. and A.E. Clarke. 1942. A natural amphidiploid from an onion species hybrid. J. Hered. 33:25-32.

Jones, H.A. and A.E. Clarke. 1943. Inheritance of male sterility in the onion and the production of hybrid seed. Proc. Amer. Soc. Hort. Sci. 43:189-194.

Kik, C. 2008. Allium genetic resources with particular reference to onion. Acta Hort. 770:135-138.

King, J.J., J.M. Bradeen, O. Bark, J.A. McCallum, and M.J. Havey. 1998. A low-density genetic map of onion reveals a role for tandem duplication in the evolution of an extremely large diploid genome. Theor. Appl. Genet. 96:52-62.

Klaas, M. and N. Friesen. 2002. Molecular markers in Allium, p. 159186. In: Rabinowitch, H.D. and L. Currah (eds.). Allium crop science: Recent advances. CABI Publishing, New York, NY

Kuhl, J.C., F. Cheung, Q. Yuan, W. Martin, Y. Zewdie, J. McCallum, A. Catanach, P. Rutherford, K.C. Sink, M. Jenderek, J.P. Prince, C.D. Town, and M.J. Havey. 2004. A unique set of 11,008 onion expressed sequence tags reveals expressed sequence and genomic differences between the monocot orders asparagales and poales. Plant Cell $16: 114-125$.

Leigh, F., V. Lea, J. Law, P. Wolters, W. Powell, and P. Donini. 2003. Assessment of EST- and genomic microsatellite markers for variety discrimination and genetic diversity studies in wheat. Euphytica 133:359-366

Leite, D., C.R. Galmarini, and M.J. Havey. 1999. Cytoplasms of elite open-pollinated onions from Argentina and Brazil. Allium Improvement Nwsl. 9:1-4.

Martin, W., J. McCallum, M. Shigyo, J. Jakse, J. Kuhl, N. Yamane, M. Pither-Joyce, A. Gokce, K. Sink, C. Town, and M. Havey. 2005. Genetic mapping of expressed sequences in onion and in silico comparisons with rice show scant colinearity. Mol. Genet. Genomics 274:197-204.

Masuzaki, S., N. Araki, N. Yamane, N. Yamauchi, T. Wako, A. Kojima, and M. Shigyo. 2006a. Chromosomal locations of microsatellites in onion. HortScience 41:315-318.

Masuzaki, S., M. Shigyo, and N. Yamauchi. 2006b. Direct comparison between genomic constitution and flavonoid contents in Allium multiple alien addition lines reveals chromosomal locations of genes related to biosynthesis from dihydrokaempferol to quercetin glucosides in scaly leaf of shallot (Allium cepa L.). Theor. Appl. Genet. 112:607-617.

McCallum, J. 2007. Onions, p. 331-347. In: Kole, C. (eds.).Genome mapping and molecular breeding in plants. Vol. 5. Vegetables. Springer, Berlin, Germany.

McCallum, J., A. Clarke, M. Pither-Joyce, M. Shaw, R. Butler, D. Brash, J. Scheffer, I. Sims, S. van Heusden, M. Shigyo, and M. Havey. 2006a. Genetic mapping of a major gene affecting onion bulb fructan content. Theor. Appl. Genet. 112:958-967.

McCallum, J., M. Pither-Joyce, M. Shaw, F. Kenel, S. Davis, R. Butler, J. Scheffer, J. Jakse, and M.J. Havey. 2006b. Genetic mapping of sulfur assimilation genes reveals a QTL for onion bulb pungency. Theor. Appl. Genet. 114:815-822.

McCallum, J.A., M.D. Pither-Joyce, and M.L. Shaw. 2002. Sulfur deprivation and genotype affect gene expression and metabolism of onion roots. J. Amer. Soc. Hort. Sci. 127:583-589.

Neff, M., E. Turk, and M. Kalishman. 2002. Web-based primer design for single nucleotide polymorphism analysis. Trends Genet. 18:613615

Ohara, T., Y.S. Song, H. Tsukazaki, T. Wako, T. Nunome, and A. Kojima. 2005. Genetic mapping of AFLP markers in japanese bunching onion (Allium fistulosum). Euphytica 144:255-263.

Payne, R.W., D.A. Murray, S.A. Harding, D.B. Baird, and D.M. Soutar. 2006. Genstat for windows. 9th Ed. VSN International, Hemel Hempstead, UK.

Peffley, E. and C. Orozco-Castillo. 1987. Polymorphism of isozymes within plant introductions of Allium cepa L. HortScience 22:956957.

Rabinowitch, H.D. and R. Kamenetsky. 2002. Shallot (Allium cepa, aggregatum group), p. 409-430. In: Rabinowitch, H.D., and L. Currah (eds.). Allium crop science: Recent advances. CABI Publishing, New York, NY.

Reif, J., S. Hamrit, M. Heckenberger, W. Schipprack, H. Peter Maurer, M. Bohn, and A. Melchinger. 2005. Genetic structure and diversity of european flint maize populations determined with SSR analyses of individuals and bulks. Theor. Appl. Genet. 111:906-913.

Rouamba, A., M. Sandmeier, A. Sarr, and A. Ricroch. 2001. Allozyme variation within and among populations of onion (Allium cepa $\mathrm{L}$.) from West Africa. Theor. Appl. Genet. 103:855-861.

Rozen, S. and H. Skaletsky. 2000. Primer3 on the WWW for general users and for biologist programmers, p. 365-386. In: Krawetz, S., and S. Misener (eds.). Bioinformatics methods and protocols: Methods in molecular biology. Humana Press, Totowa, NJ.

Schuelke, M. 2000. An economic method for the fluorescent labeling of PCR fragments. Nat. Biotechnol. 18:233-234.

Tanikawa, T., M. Takagi, and M. Ichii. 2002. Cultivar identification and genetic diversity in onion (Allium cepa L.) as evaluated by random amplified polymorphic DNA (RAPD) analysis. J. Jpn. Soc. Hort. Sci. 71:249-251.

Tsukazaki, H., H. Fukuoka, Y.-S. Song, K.-I. Yamashita, T. Wako, and A. Kojima. 2006. Considerable heterogeneity in commercial $\mathrm{F}_{1}$ varieties of bunching onion (Allium fistulosum) and proposal of breeding scheme for conferring variety traceability using SSR markers. Breed. Sci. 56:321-326.

van der Meer, Q.P. and J.N. de Vries. 1990. An interspecific cross between Allium roylei Stearn and Allium cepa L., and its backcross to $A$. cepa. Euphytica 47:29-31.

van Heusden, A.W., J.W. van Ooijen, R. Vrielink-van Ginkel, W.H.J. Verbeek, W.A. Wietsma, and C. Kik. 2000. A genetic map of an interspecific cross in Allium based on amplified fragment length polymorphism $\left(\right.$ AFLP $\left.^{\mathrm{tm}}\right)$ markers. Theor. Appl. Genet. 100:118126.

Wang, H.Y., Y.M. Wei, Z.H. Yan, and Y.L. Zheng. 2007. EST-SSR DNA polymorphism in durum wheat (Triticum durum L.) collections. J. Appl. Genet. 48:35-42. 


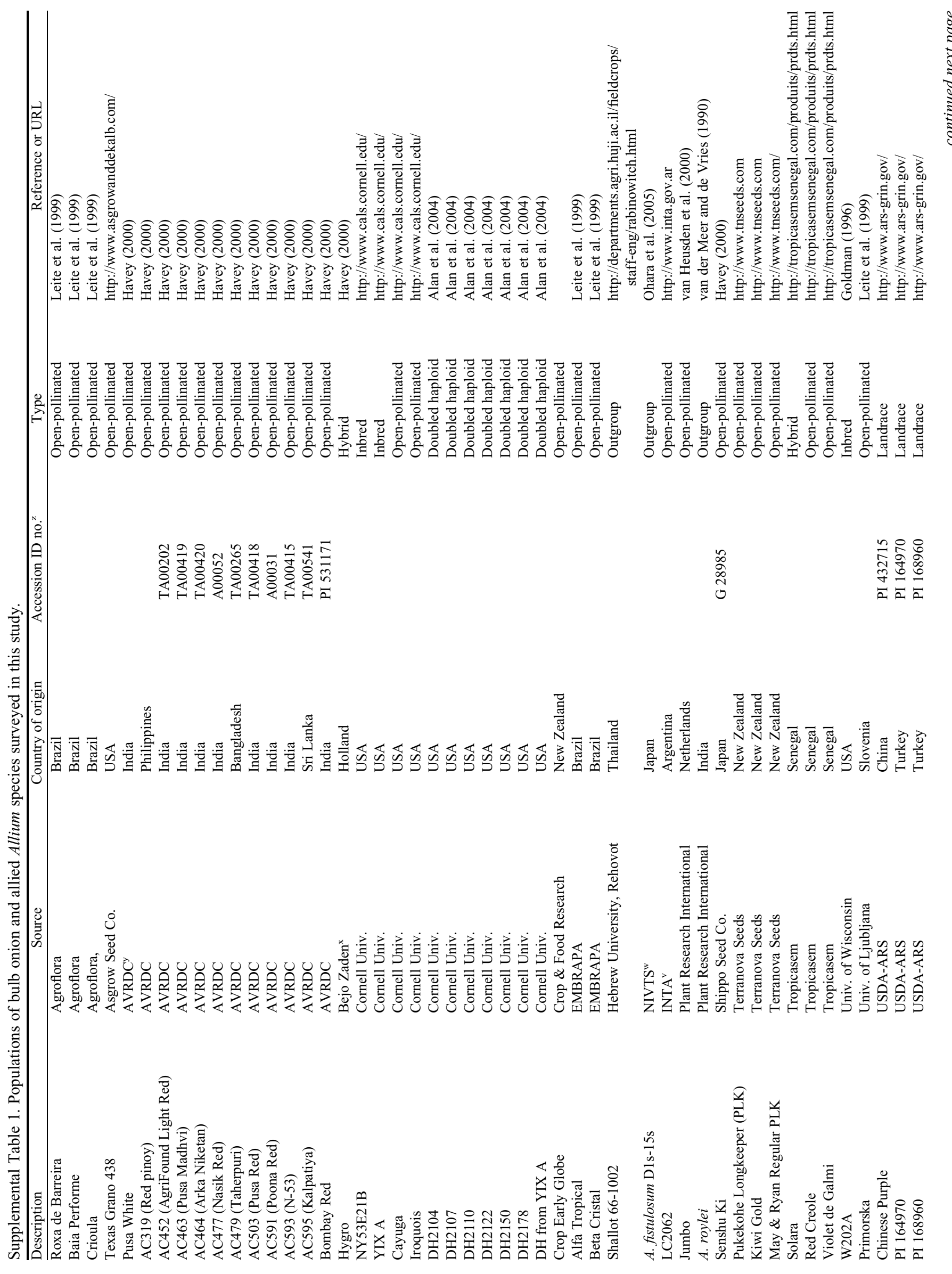




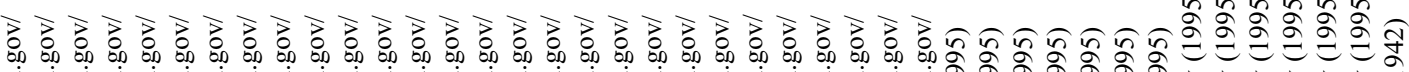

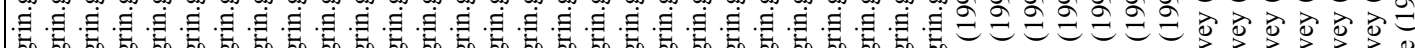

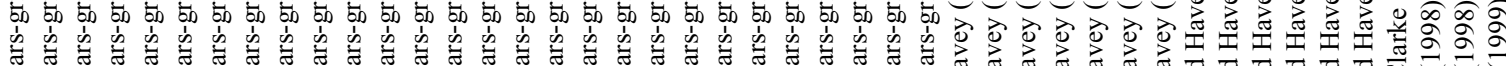

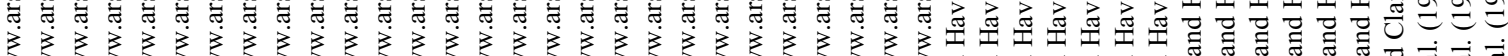

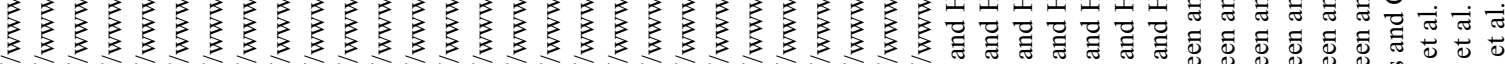

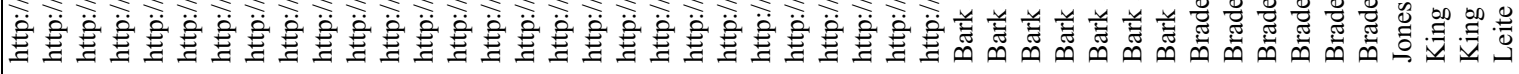

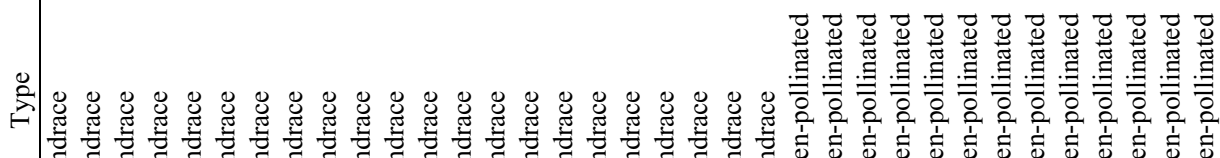

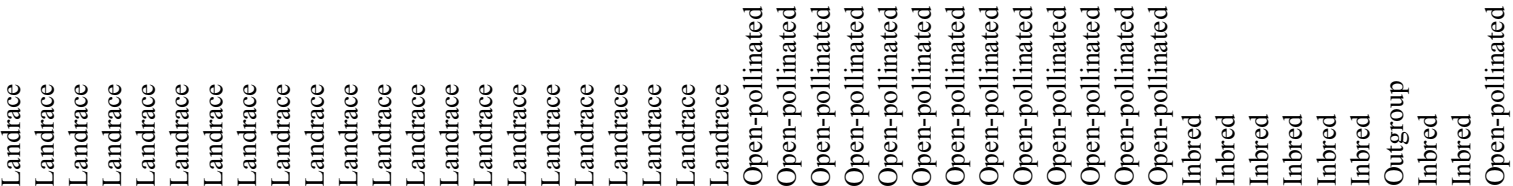

$\stackrel{8}{9}$

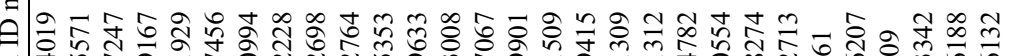

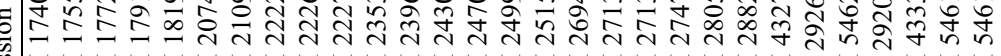

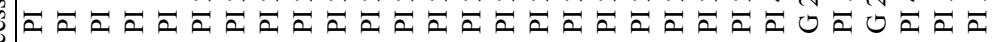

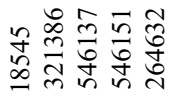

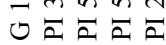

:

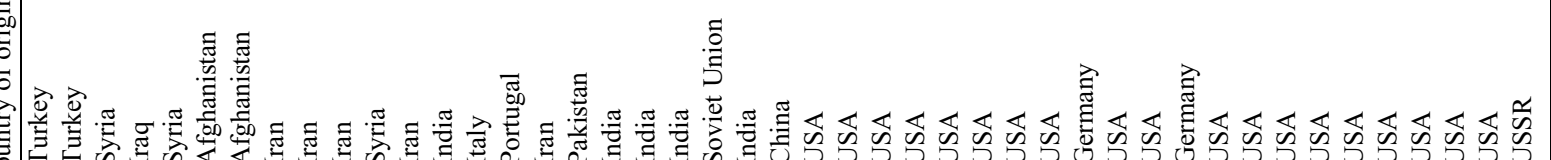
ठํ. 幽

की 00 के

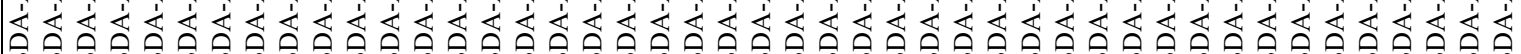

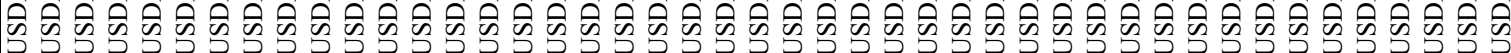

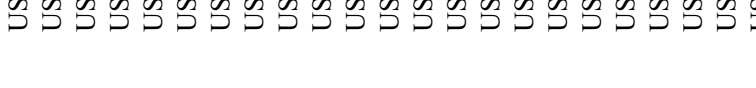

을

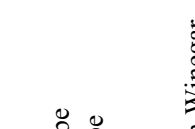

离

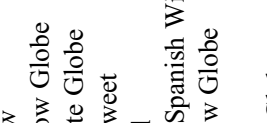

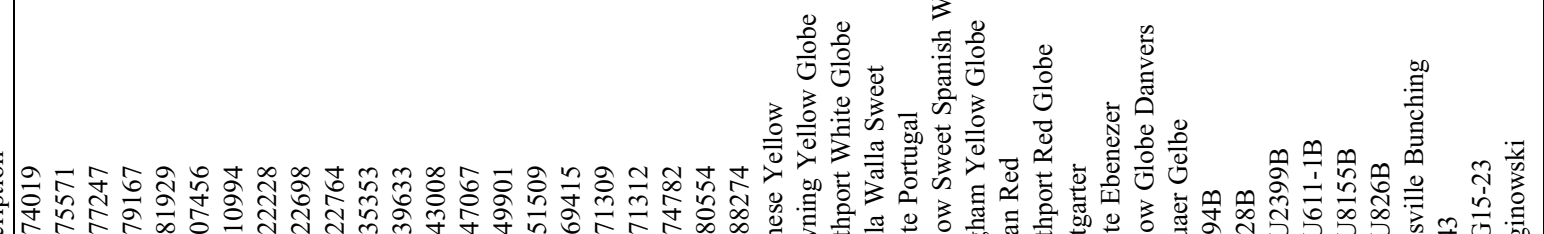

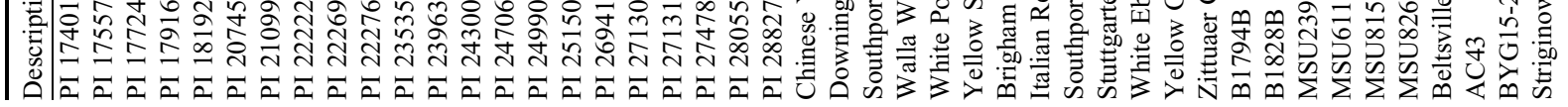

